\title{
LA VIDA DE DOMINGUITO: CIUDADANÍA, PATERNIDAD Y GUERRA EN DOMINGO FAUSTINO SARMIENTO
}

\author{
Alejandra Josiowicz \\ é investigadora assistente no Instituto Interdisciplinario de Estudios de Genero \\ (IIEGE-FFyL/UBA) e do Consejo Nacional de Investigaciones Científicas y Técnicas (CONICET). \\ Buenos Aires, Argentina.E-mail:<alejandra.josiowicz@gmail.com> \\ http://dx.doi.org/10.1590/0102-039068/103
}

Los estudios más relevantes sobre Sarmiento han pensado su obra y su trayectoria a lo largo de un eje estructurado por dos alternativas predominantes: Carlos Altamirano y Beatriz Sarlo (1997) han subrayado su defensa de los valores laico-burgueses, como autodidacta y self-made man, hijo de sus obras, para el cual la educación - la lectura como paradigma pedagógico -, constituye el resorte fundamental de acceso a la ciudadanía, arma contra la barbarie y condición de la emancipación intelectual ante la sociedad tradicional $^{1}$. Por su lado, Halperín Donghi $(1980,1989,1994)$ ha subrayado su nostalgia por el pasado colonial, su concepción de la educación como herramienta de conservación social y su fe en una nobleza ilustrada dada por el linaje, de la cual se presenta como heredero y que estaría destinada a ejercer el poder político en Argentina. Este ensayo analiza la representación del hijo como escenificación del encuentro de ambas lógicas - de hecho, entrelazadas en el pensamiento

\footnotetext{
1 De cualquier modo, los autores aclaran que Sarmiento le confiere a su reconstrucción genealógica un sentido polivalente. Para una lectura más reciente, ver Sarlo (2012).
} 
de Sarmiento -: Dominguito encarna el modelo del joven ilustrado, ciudadano en armas, que combina el protagonismo de una élite letrada y patriótica destinada a gobernar - dada por la valentía y el arrojo militar - con la apertura de la sociedad a una idea de valoración en base a las capacidades y voluntades individuales, en que la educación funcionaría como motor fundamental del acceso a la ciudadanía. Así, el ensayo busca responder a la pregunta: ¿De qué modo se relacionan filiación y política en Sarmiento, por muchos considerado padre de la patria y de la escuela argentina? ¿Cuáles son los sentidos políticos del modo en que concibe la paternidad y, particularmente, del modo en que representa a su hijo, en la biografía? ¿Cuál es la relación entre su concepción de la infancia y la formación de una Argentina moderna? Dado su legado duradero en el sistema de educación primaria argentina y en los discursos sobre la educación como núcleo de resolución de los problemas sociales 40 del país, el sentido en que Sarmiento concibió la infancia y la juventud como modelos de ciudadanía adquiere una singular relevancia. Si tenemos en cuenta que las dos últimas décadas del Siglo XX implicaron drásticos cambios en la composición de la población argentina, con la llegada de olas masivas de inmigrantes, el crecimiento demográfico, la creciente urbanización, la ampliación educativa y la instauración de leyes de escolaridad pública y obligatoria (Halperin Donghi, 1997, p. 291), responder esas preguntas a partir de la escritura biográfica de La vida de Dominguito se vuelve particularmente crucial.

\section{Introducción: las dos versiones de La vida de Dominguito}

La vida de Dominguito (1886) de Domingo Faustino Sarmiento (1811-1888), un texto casi completamente olvidado por los estudios críticos, es una biografía de su hijo adoptivo, Domingo Fidel Sarmiento, nacido en Santiago de Chile en 1845 y muerto en la Guerra del Paraguay en 
1866. La crítica aún debate si Dominguito fue, de hecho hijo biológico de Sarmiento, fruto de una unión extramatrimonial con la madre o si, sin ningún lazo de sangre con él, simplemente fue adoptado luego de fallecido su padre ${ }^{2}$. Lo cierto es que, después de compartir algunos años en Chile, Sarmiento y el hijo perderían contacto en 1861 cuando, ya separado de su madre, el padre parte hacia San Juan y el hijo prosigue hacia Buenos Aires. Poco tiempo después, el joven es nombrado capitán en el ejército argentino de la Guerra del Paraguay y fallece en 1866 en Curupaytí, mientras Sarmiento se encontraba en Estados Unidos. Crucial aquí son tanto el acto de adopción como la necesidad de repensar el lazo paterno-filial a través de la biografía, cuestiones que serán retomadas a lo largo de este ensayo.

Existen dos versiones de La vida de Dominguito. La primera, un conjunto de apuntes que Sarmiento escribió en 1867 cuando actuaba como Ministro Plenipotenciario en Washington, después de recibir la noticia de la muerte del hijo, no fue publicada en vida del autor y continuó inédita hasta hace pocos años ${ }^{3}$. La segunda fue publicada por Sarmiento en 1886, con el extenso título de La vida de Dominguito. In memoriam del valiente y deplorado capitán Domingo Fidel Sarmiento muerto en Curupaiti a los veinte años de edad. Autor de varios escritos, biografias y correspondencias y traductor de "París en América". El texto apareció como un tomo con motivo del vigésimo aniversario del fallecimiento del hijo, dos años antes de la muerte de Sarmiento en 1888.

\footnotetext{
2 Porfirio Fariña Nuñez (1934) discute extensamente la "dudosa" filiación de Dominguito, y opta por atribuir la paternidad biológica a Sarmiento. Enrique Anderson Imbert (1975) expone una hipótesis similar.

${ }^{3}$ Los manuscritos fueron editados con el título de La Vida de Dominguito en 2000 por el Fondo Nacional de las Artes a cargo de Javier Fernández. A partir de aquí, cito la versión de 1867 como La vida de Dominguito y la de 1886 como La vida de Dominguito. In memoriam. Por razones prácticas, para el análisis, citaré sobre todo de la versión reeditada por A. Belin Sarmiento en 1900 como "Vida de Dominguito".
} 
Se trata de textos marcadamente distintos en su carácter e intencionalidad, así como vinculados a momentos diferentes de la trayectoria política e intelectual de Sarmiento: la primera versión, escrita en el momento mismo del duelo, en Estados Unidos, tiene un carácter íntimo y literario, mientras que la segunda, de carácter público y patriótico, responde a la búsqueda de un legado y de un modelo de ciudadanía para la Argentina moderna. En la primera, Sarmiento, inmerso en el dolor íntimo y personal por la pérdida del hijo, hace de la escritura biográfica un instrumento del duelo, dotada de un poder consolatorio. El dolor del duelo genera un quiebre en la subjetividad del autor: allí el padre doliente aparece por sobre el hombre público y el estadista. La primera versión de Vida de Dominguito se adentra en el sentimiento paterno-filial a través de una noción espiritualista de comunicación entre vivos y muertos, de una celebración y sentimentalización de los lazos familiares y, en 42 particular, de la relación paterno-filial. Escribe Sarmiento desde New York en carta a Mary Mann en 1866:

Tengo que conformarme, y ya estoy más resignado, aunque el recuerdo de sus gracias infantiles, sus juegos conmigo me haga llorar más que la idea de su trágica y sangrienta muerte. No puedo recordarlo sino alegre y riendo y esto me hace sufrir más. Estos días estaré más tranquilo. Le agradezco su tierno interés y quedo su desconsolado amigo (Sarmiento, 2000, p. 17).

Sarmiento exalta el sentimiento paterno, que se encarna en el recuerdo cariñoso del padre entrelazado con el niño en el juego. Como texto ligado al sentimiento de afecto paterno-filial, la primera versión de Vida de Dominguito adquiere un status casi clandestino en la obra de Sarmiento (2000, p. 22). Sería una suerte de "fraude", en palabras de Sarmiento, por el cual el padre doliente intenta 
restituir, como por una suerte de conjuro, al hijo perdido. Es ese carácter casi ilícito lo que determina la resistencia de Sarmiento a su publicación, y lo que lo distingue de modo más agudo de la segunda versión.

En el texto de 1886, el núcleo principal no está en el dolor por la pérdida, sino en la representación del fin heroico del hijo en la batalla y de su muerte patriótica, como modelo de civismo y figuración del legado de Sarmiento para la Argentina futura. El texto emula, en su solemnidad, la estructura de un monumento necrológico, formado por una serie de documentos y testimonios que reconstruyen la vida de Dominguito, destinados a exaltar su figura y a conferir propósito e inteligibilidad a su muerte ${ }^{4}$. Se trata de una estructura formada por tres secciones, todas ellas enmarcadas por la voz de Sarmiento. La primera sección, de 29 páginas, presenta una serie de retratos de Dominguito: un retrato pictográfico, una dedicatoria de Sarmiento, una semblanza encomiástica escrita por Olegario Ojeda, a continuación, una introducción de Sarmiento, seguida por una serie de coronas fúnebres, notas de pésame y dedicatorias de personalidades públicas y una conclusión del autor. La segunda sección, que abarca 148 páginas, consiste en la narración, por parte del padre, de las memorias de la infancia y adolescencia de Dominguito y, para los sucesos posteriores a su último encuentro en San Juan, se apoya en cartas y testimonios de su madre, de colegas de estudios y de compañeros de la batalla, así como en fragmentos del cuaderno de apuntes que llevaba en el momento en que murió, todos materiales comentados por Sarmiento. La tercera y última sección, que ocupa 174 páginas, recopila escritos del propio Dominguito: sus “Apreciaciones militares” (crónicas de la Guerra del Paraguay aparecidas en los periódicos), sus

\footnotetext{
${ }^{4}$ Nicolás Rosa ha comparado al texto con un monumento necrológico: "La escritura de la bio-grafía (sic) de Dominguito es escritura de un necro-logos: otra forma de la inscripción lapidaria” (Rosa, 1990, p. 104).
} 
ensayos de crítica literaria, el prólogo a su traducción de "Paris en América" (de E. Laboulaye), ensayos de tipo biográfico, conferencias y discursos que pronunció y las actas del club de Estudiantes en que participaba, seguidos de un poema laudatorio de Agustín P. Justo. Los materiales se presentan intercalados con las memorias de Sarmiento, sus observaciones y explicaciones, que guían la narración. Esta estructura, que enmarca la biografía en una serie de testimonios y documentos públicos y privados, tiene como propósito posicionar a Dominguito entre los grandes hombres de su generación, a través de la cita de intelectuales y hombres políticos que actúan como testigos y autoridades legitimadoras. De este modo, el aparato monumental y documental legitima y corrobora las memorias paternas y, a su vez, la narración del padre confiere significación a estos materiales, como confirmación de la muerte patriótica del hijo y consagración de ambos como héroes patrios, modelos 44 de gloria nacional.

Por otro lado, el texto pone en escena el impacto de la Guerra del Paraguay (1864-1870) en el escenario histórico-político, sobre todo, el modo en que la guerra repercutió en la consolidación del Estado nacional argentino - fue su primera guerra moderna - y en el equilibrio geopolítico entre las potencias de la región. La Guerra del Paraguay fue el conflicto más sangriento y extenso del Siglo XIX después de las contiendas por la emancipación y cerró el largo ciclo de inestabilidad posterior a las independencias (Halperín Donghi, 1980, p. 57). Se trató de un momento decisivo en la construcción del Estado Nacional argentino, garantizando la hegemonía del gobierno nacional sobre las provincias. Por su carácter polémico y la falta de consenso inicial acerca de su justificación y pertinencia, la Guerra hizo emerger una serie de resistencias al proyecto centralizador del Estado argentino. El gobierno de Mitre sufrió enormes dificultades para conseguir que las provincias enviasen su proporción de 
voluntarios para componer el ejército: parte de la población se resistía a luchar contra Paraguay en alianza con Buenos Aires, a punto tal que las sublevaciones y deserciones adquirieron proporciones preocupantes (Doratioto, 2002). Si en el caso del Imperio brasileño, el conflicto bélico generó entusiasmo patriótico entre las masas populares, provenientes de las provincias del Norte y del Nordeste, en el caso argentino se dio una tendencia contraria, dado que el reclutamiento tuvo éxito, sobre todo, entre la población porteña y entre los jóvenes educados de las élites (Leuchars, 2002). Sin embargo, a pesar de su carácter polémico, la guerra le impuso al Estado argentino, y en particular a su aparato militar, un ritmo de expansión tal que forzó la emergencia de un nuevo tipo de hegemonía, propia de la nación unificada y vinculada al nuevo consenso alcanzado por el gobierno central (Halperín Donghi, 1980). La guerra tuvo un papel decisivo en la posterior ampliación y modernización del ejército - que ocurriría durante la presidencia de Sarmiento - y contribuyó de modo definitivo a acelerar el proceso de formación nacional.

Sarmiento fue un activo defensor de la causa bélica: publicó en 1866, en Estados Unidos, un folleto de 48 páginas titulado Revelations of the Paraguayan War and the Alliances of the Atlantic and the Pacific - que apareció sin firma y sin mención del autor - en el que defendía la posición de la Triple Alianza contra las agresiones del Paraguay y caracterizaba al Mariscal Francisco Solano López como un dictador corrupto y sanguinario. Asimismo, en otros textos de la época, Sarmiento se presentaba como conductor exitoso de la lucha militar contra los últimos caudillos y capaz de llevar a buen término la Guerra del Paraguay, cuyo fin tuvo lugar durante su presidencia. En la versión de 1886 de Vida de Dominguito, Paraguay aparece como una "oscura y misteriosa China americana” (Sarmiento, 1900, p. 246), nación bárbara, ciegamente obediente a la voluntad de Solano López y 
su "disciplina del terror hereditario", quien habría sido déspota y demagogo: la guerra se justificaría, por lo tanto, por la "necesidad de vengar agravios de un tirano atrabiliario" (Sarmiento, 1900, p. 245).

La Vida de Dominguito, por otro lado, está íntimamente ligado a los últimos años de vida de Sarmiento. En la Argentina de 1880, Sarmiento adquiere una visión particularmente pesimista de la vida política: se siente cuestionado y rodeado de enemigos y se ve impelido a revindicar su actuación político-militar durante la guerra civil y a resaltar la faceta militar de su legado para la Argentina futura ${ }^{5}$. La Guerra del Paraguay y el fallecimiento de su hijo en el conflicto bélico se ofrecen como modos de subrayar justamente esa faceta y ese legado: firma el texto como D.F. Sarmiento, "General de División" y lo dedica a los "amigos de infancia, a los concolegas de estudios y a los compañeros de armas" de Dominguito, apelando a los hombres de la Generación de 1880 - que habían sido jóvenes en 1860 - entre quienes se posiciona como antecedente y predecesor. Escribe en la Introducción al texto:

¿No será disculpable su anciano padre ensordecido ya por el fragor de instituciones que se derrumban, perdida la voz a fuerza de predicar en el desierto sesenta años sin tregua, si quiere recoger todavía, al borde de su propia tumba, los fragmentos del rico vaso a que pensó trasegar su pensamiento, para que continuara la obra otros tantos, y que cayendo de manos del sacerdote que lo presentaba al pueblo ante el altar de la patria se rompió? (Sarmiento, 1900 , p. 182)

\footnotetext{
${ }^{5}$ Halperín Donghi ha descripto el pesimismo de la última etapa de Sarmiento y su posición incómoda ante el ascenso de Julio A. Roca y su tradición federalista al poder (1980).
} 
La vida de Dominguito pone en escena la percepción de aislamiento político e ideológico que inundó a Sarmiento en sus últimos años, así como la necesidad de reafirmar el modo en que figurará en la memoria nacional. Sintiéndose cercano a la muerte, desoído y carente de herederos o continuadores, escribe la biografía del hijo como un modo de llenar ese vacío y esa falta y de darle forma, en la escritura, a su legado para la Argentina moderna.

\section{La vida de Dominguito: texto entre textos}

La vida de Dominguito ocupa un lugar particular entre los textos de Sarmiento: es la última de sus biografías, está en relación de proximidad con su corpus autobiográfico y se ubica en una zona cercana a sus textos pedagógicos, así como a sus últimos discursos y necrologías. Como texto que ahonda en lo paterno-filial, en la relación entre Sarmiento padre y su hijo, La vida de Dominguito es tanto un texto biográfico y autobiográfico como un texto pedagógico y una metodología. Está ligado a sus traducciones de textos morales y biografías pedagógicas, La conciencia de un niño y Vida de Jesucristo, utilizados como literatura escolar y pedagógica en las escuelas chilenas (Sarmiento, 1899, p. 20), así como a su Método de Lectura Gradual de enseñar a leer el Castellano (1845). Dicho manual escolar despliega la metodología para el aprendizaje de la lectura, la ortografía y la gramática que sería aplicada en la educación de Dominguito, como modelo y método pedagógico: varias de sus lecciones se hallan reproducidas en el texto. Además, La Vida de Dominguito puede leerse junto con sus textos de reflexión pedagógica: sus numerosos artículos sobre métodos pedagógicos y sobre administración y organización de la educación (Sarmiento, 1899), con De la educación popular (1849) y Educación común (1855), en que resalta el papel de la instrucción pública, primaria y elemental en un régimen republicano. 
Por otro lado, Vida de Dominguito también se relaciona con las biografías de escritores y de políticos estadounidenses que Sarmiento había leído y que consideraba centrales en su propia formación: La vida de Benjamin Franklin y la Vida de Abraham Lincoln. Sarmiento consideraba La Vida de Franklin un texto modélico: afirma ser producto de su lectura y emulación y declara que todo niño sudamericano debía querer ser un "Franklincito" ${ }^{6}$. Es el texto cuya traducción le encarga a Juan María Gutiérrez el que lee a Dominguito y utiliza como modelo fundamental para su educación: "El nombre de Franklin resonó muchas veces en los oídos infantiles del Capitán Sarmiento y sus doctrinas empezaron desde su adolescencia a formar parte de su naturaleza" (Sarmiento, 1900, p. 309). Dominguito aprende la "filosofía práctica" de Franklin, el "espíritu moderno, industrial", y lo emula como "escritor, como republicano y como hombre de Estado" (Sarmiento, 1900, p. 310). Por otro lado, Sarmiento escribe una biografía de Lincoln, titulada Vida de Abraham Lincoln (publicada en 1866 en Nueva York por la editora Appleton \& Company), en que subraya la formación auto-didacta de Lincoln, su pasión por el estudio, su búsqueda de superación personal y la carencia de una formación escolar tradicional, características que sirven para narrar la infancia de Dominguito, si bien en el caso de este último, como advierte Sarmiento, el proceso aún incompleto de formación nacional dificulta el avance del discípulo.

La biografía, para Sarmiento, funciona como una suerte de pedagogía de la historia, cruce entre historia y manual. Como Émile ou de l'éducation (1762), de Jean Jacques

\footnotetext{
${ }^{6}$ Sylvia Molloy ha observado al respecto: "He wished to put Franklin's Autobiography on school curricula, so that every student, on reading it, would wish to be a little Franklin" (1992, p. 214). ["Deseaba incluir la autobiografía de Franklin en los programas escolares, de modo que todo estudiante, al leerla, deseara ser un Franklincito."] (trad. del autor)
} 
Rousseau, Vida de Dominguito narra la educación del discípulo y funciona como un modelo de educación destinado a la formación de formadores. La vida y educación de Dominguito, de este modo, son pensadas en relación de continuidad - y también de contraste - con las biografías de hombres norteamericanos, en su carácter modélico, una herramienta metodológica a la vez que un manual de ciudadanía, que da cuenta de los conflictos y retrocesos en el proceso de formación (tanto individual como colectiva).

Por otro lado, Vida de Dominguito se vincula también con el corpus autobiográfico de Sarmiento, con Mi defensa (1842) y Recuerdos de Provincia (1849-1850), dada la estrecha ligazón entre biografías y autobiografías que la crítica ya ha señalado en su obra. En Vida de Dominguito, la escritura de la vida del hijo se entremezcla con la de la vida del padre, una se extiende en la otra, lo que le confiere un marcado carácter autobiográfico al texto. Se trata de una biografía del hijo en que Sarmiento se lee a sí mismo, entretejiendo al biografiado con el yo del biógrafo. El hijo hereda las glorias del padre y el padre, a su vez, construye su propio legado tomando como punto de partida las hazañas del hijo y la relación paterno-filial ${ }^{7}$.

Así, si en Recuerdos de Provincia (1849-1850) Sarmiento se construye como hijo y eslabón en una cadena de antepasados prestigiosos, en Vida de Dominguito construye su progenie y legado futuro a partir de la vida y la muerte del hijo. Adopta al hijo, Dominguito, dándole el nombre, volviéndolo parte de su estrategia simbólica y motor de su escritura. De este modo, reclama para Dominguito la pertenencia a

\footnotetext{
7 Esta ha sido la característica del texto más señalada por la crítica: Nicolás Rosa afirma que allí la propia vida se extiende en la del hijo; Sylvia Molloy advierte que Sarmiento hace del hijo una copia de sí mismo, y de su biografía una especie de autobiografía (1992, p. 144); Enrique Anderson Imbert la incluye en el corpus de su obra autobiográfica y argumenta que el texto retrata a Sarmiento más que a Dominguito (1967, p. 170). Otro de los contados estudios es el texto inédito, mayormente fáctico y biográfico, de Brizuela Aybar (1988).
} 
un linaje distinguido del cual se presenta como punto de partida y fundador. Ahora bien, si en Recuerdos de Provincia, Sarmiento se figuraba como heredero de una nobleza al mismo tiempo democrática, de talento, y encarnada en el linaje (Halperín Donghi, 1980, p. 24), en Vida de Dominguito reclama para Dominguito una pertenencia análoga, como heredero de un linaje de patriotismo e ilustración indispensables para el buen gobierno. La pertenencia a un grupo, la destreza gobernante y la ilustración van de la mano en Vida de Dominguito, una confirma incesantemente a la otra, leídas inclusive en los actos de indisciplina, los fracasos escolares o intentos de transgresión del hijo, vistos como inequívocas pruebas de audacia y voluntad de gobierno. A la vez, Dominguito escenifica la emergencia de nuevos modos democráticos de acceso a la ciudadanía a partir de las capacidades individuales - la inteligencia, el ingenio, la destreza en las armas y el intelecto ${ }^{8}$. Se trata de una concepción 50 ambivalente de la paternidad, a la vez como transmisión de una herencia y como lazo electivo y democrático que lleva implícita una idea de autodeterminación.

\section{Vida de Dominguito como biografía: historia, memoria y manual}

En términos teóricos, la biografía constituye un tipo de escritura memorialística en que el autor registra e interpreta los recuerdos acerca de otro, evocando la propia subjetividad en el pasado (Miceli y Myers, 2016). La biografía moderna, en su avatar menos académico, se basa en el recuerdo y la experiencia que el biógrafo ha tenido de su objeto: es concebida en función del vínculo que establece con el biografiado y, por lo tanto, está más cercana al universo de las memorias (Miceli y Myers, 2016). El género

\footnotetext{
8 Esto ha sido analizado por Adolfo Prieto en la escena del ingreso escolar en Recuerdos de Provincia (1996, p. 60).
} 
biográfico responde al empeño de construcción del yo en confrontación con un otro: en una suerte de gesto antropofágico, el biógrafo se identifica y se nutre de la fuerza del biografiado, implica su subjetividad y establece con él una relación especular (Dosse, 2009). Como parte del proceso de laicización de la memoria, el protagonista de la biografía moderna emerge como un héroe, un gran hombre que encarna el alma nacional, que articula lo individual y lo ejemplar, y cuyas virtudes suscitan un deseo de imitación e identificación (Dosse, 2009). La biografía constituye, de este modo, un modelo edificante que encarna y transmite valores a las futuras generaciones, sean de tipo militar o intelectual, de gestión política o capacidad creativa (Dosse, 2009). Esto es porque, como ya señaló Maurice Halbwachs, la memoria biográfica y autobiográfica tiene su raíz en la colectividad social, dado que es esencialmente social y pública (Halbwachs, 1992). Por otro lado, como Philippe Lejeune argumentó, la biografía y la autobiografía dependen de un mismo pacto referencial, un contrato de identidad que presupone un tipo de autenticidad y compromete al autor con el lector (Lejeune, 1975). Ambas intentan dar cuenta de la unidad profunda de una vida y ofrecen una impresión de totalización, por lo que revelan una tensión epistemológica entre el deseo de verdad (la voluntad de reproducir la vida de un individuo real pasado) y la dimensión estética e imaginativa, que le confiere valor artístico (Lejeune, 1975; Dosse, 2009).

Como he afirmado, en Vida de Dominguito, Sarmiento construye su propia imagen a partir de su relación con su hijo: el biógrafo se nutre del biografiado, con el que establece una relación especular. La implicación subjetiva de biógrafo y biografiado se intensifica debido al lazo paterno-filial, al ser una biografía que el padre escribe sobre el hijo. Por otro lado, allí la escritura biográfica figura como un ars moriendi, un modo de familiarizarse con la propia 
muerte, de aceptarla poniéndose en el lugar de aquel que desapareció (Dosse, 2009). Sarmiento reflexiona sobre la muerte del hijo y sobre la propia mortalidad, que se figura cercana, en el marco de una lógica patriótica y del valor militar. Con base en su participación militar y en la de su hijo, Sarmiento posiciona su legado entre los grandes hombres de la patria. Vida de Dominguito imagina la transformación de padre e hijo en monumentos necrológicos, estatuas de la historia, como parte de un linaje de grandes hombres cuyo sacrificio aseguraría la consolidación nacional.

Por otro lado, la biografía no tiene una estructura homogénea, sino ineluctablemente compuesta, en la cual convergen relatos diversos, entrelazados unos con otros, cuya hibridez y transversalidad la vuelven de difícil clasificación (Dosse, 2009). La Vida de Dominguito participa del hibridismo constitutivo que, según François Dosse, seria propio del género biográfico, situado siempre en el punto 52 de intersección de múltiples disciplinas. El texto instaura un régimen de historicidad - dada su estructura basada en el montaje y en la recopilación de testimonios y documentos escritos -, se propone actuar como texto pedagógico - que transmite valores y virtudes edificantes destinados a la imitación e identificación - y es una memoria paterno-filial. En su carácter didáctico y ejemplar, presta atención al público lector; se propone señalar a las próximas generaciones los caminos de acceso a la ciudadanía y al heroísmo patrio. Afirma Sarmiento: "A veces me viene la idea de escribir una biografía de esta vida tan rica en incidentes, tan instructiva como educación” (1900, p. 180) y agrega: "para que estimen su nombre los padres que sobreviven a sus hijos, los jóvenes que aman siempre a su patria y le consagran sus desvelos y su vida" (1900, p. 183). El texto es pensado en su carácter instructivo y pedagógico, como legado para las jóvenes generaciones futuras, al mismo tiempo que como memoria paterno-filial. 
Como memoria, registra de un modo detallista los hechos más cotidianos, anécdotas aparentemente insignificantes e íntimas de la infancia del hijo - sus palabras, ocurrencias y rebeldías, su intelecto precoz, sus observaciones ingeniosas, su atención inusitada, su carisma y su capacidad de aplicar lo que lee y oye en el círculo paterno, así como su temprano interés por cuestiones políticas. Vista a través de una mirada microscópica, la infancia de Dominguito pretende producir un efecto totalizante, que anticipa la trayectoria y el carácter ejemplar del sujeto, que se proyecta, así, sobre la gesta heroica del joven en la batalla. Sarmiento lee en el niño, en germen, las destrezas del adulto: la inteligencia del científico, la valentía del patriota, la sociabilidad del hombre público y la gloria del estadista. Como en un uso laico de la hagiografía, tradición literaria que le sirvió de modelo a Sarmiento (Altamirano y Sarlo, 1997), Vida de Dominguito postula todo en el origen, en el estado inicial: sigue una concepción teleológica de la biografía que lo ve dotado desde la infancia de todas las cualidades exigidas para ser un individuo excepcional. Centrales son, en este sentido, varios episodios iniciáticos de la infancia: el aprendizaje de la lectura y la escritura, la primera votación, el aprender a montar a caballo, a disparar y el ejercicio de sus dotes de caudillo entre los otros alumnos. Incluso cuando se basa en testimonios y documentos históricos, el texto privilegia el carácter modélico, que une el héroe a su destino providencial. Así, la infancia aparece como reveladora de la efigie póstuma del hijo: Dominguito aparece entero, listo desde el inicio para enfrentar todas las pruebas sin sufrir esencial transformación. Una vez expuesto, el retrato se vuelve ejemplo de vida y modelo a imitar.

Sin embargo, junto a este carácter en cierta medida inmutable, Dominguito también es visto como un héroe tensionado entre sus propios talentos y virtudes y la interacción con fuerzas adversas, tanto internas como externas. 
Así, su formación se frustra, una y otra vez, por su dificultad de sujetarse a reglas, dada su personalidad marcada por el exceso y la desmedida. Si en el colegio y la universidad exhibe sus dotes intelectuales y los conocimientos que le vienen de lo que oye y ve en el círculo del padre, lo cual lo posiciona como un líder carismático, sus estudios se ven sistemáticamente interrumpidos ya sea por la rebeldía del discípulo o por la atmósfera de inestabilidad política que lo rodea. Como cabecilla de travesuras estudiantiles, es castigado y expulsado de los colegios chilenos y argentinos a los que asiste y, ya en la universidad, abandona los estudios y se enrola en el ejército. La desmesura del héroe aparece aquí en relación estrecha con el contexto político de una nación en formación que arrastra, en la perspectiva de Sarmiento, trazos heredados de barbarie (Sarmiento, 1900, p. 219). Esta suerte de imposibilidad de desarrollo, que Sarmiento atribuye a una herencia defectuosa que 54 sería una marca de la nacionalidad, estaría en la base de la formación fallida de Dominguito, nacido durante el régimen de Rosas, seis años antes de la batalla de Caseros (Sarmiento, 1900, p. 186). La amenaza que la barbarie representaría al orden político nacional se traslada, por una operación metonímica, al propio carácter del hijo. Testigo de la inmadurez política que sería propia de los "pueblos infantiles", educado en sus "pasiones", "terrores" y "escándalos", Dominguito padece de una inclinación correlativa al desorden y a la inestabilidad (Sarmiento, 1900, p. 208). La vida de Dominguito encarna, así, el espíritu de una época y sigue una ley inexorable de la historia: atravesado por la política desde la infancia, su destino ineluctable es la guerra, el sacrificio por la causa nacional.

Vida de Dominguito pone en escena una concepción de la biografía en la que el sacrificio heroico por la patria cumple un papel fundamental: como "gran hombre", su muerte bélica se justifica como un paso en la consolidación 
nacional. Como ha advertido François Dosse, en las biografías del Siglo XIX, la identidad patriótica exalta los valores heroicos de ciertas figuras cuyo coraje en combate y disposición para el sacrificio nutren la idea de una República próxima a la guerra (1900, p. 168). Para ilustrar el carácter patriótico y ejemplar de la hazaña bélica de Dominguito, aparecen citados numerosos testimonios, las cartas de su madre, así como los apuntes y escritos del hijo. Sarmiento se hace responsable y se inscribe en su destino providencial: "Dios me lo perdone si hay que pedir perdón de que el hijo muera en un campo de batalla, pro patria, pues yo lo vine dirigiendo hacia su temprano fin" (1900, pp. 245-246). El padre se presenta como artífice principal del sacrificio heroico de Dominguito. Sarmiento le adjudica a Dominguito - y, con él, a los jóvenes de las élites porteñas -, un rol providencial, como representantes de la nación como un todo, defensores de los ideales ilustrados y de un destino histórico patrio, contra la barbarie heredada. Dominguito estaría destinado a encontrar su vocación cívica y su genio en virtudes como la elegancia, el heroísmo, la virilidad, todas vinculadas al papel que le adjudica Sarmiento a las élites militares e ilustradas en el proceso de consolidación nacional.

\section{Modos de la ciudadanía: entre las armas y las letras}

La categoría de ciudadanía, su definición y constitución, fue central en el proceso de consolidación del Estado Nacional argentino en el período posterior a las independencias, durante la segunda mitad del Siglo XIX. Se trató de un proceso marcado por avances y retrocesos en la expansión y desarrollo de los derechos políticos entre camadas más amplias de la población. Así, la extensión del "pueblo" fue objeto de debate entre las élites, que tenían visiones distintas sobre las barreras de inclusión y exclusión de esos derechos (Sábato, 2001). La Vida de Dominguito pone en escena los impases en este proceso de definición 
y expansión de los derechos políticos y de la ciudadanía. El texto escenifica el papel relativamente marginal que, en este momento del pensamiento de Sarmiento, le cabía a la vía electoral, en comparación con la educación y con la participación en círculos y clubes culturales y literarios, y sobre todo, ante la relevancia que el camino militar y la intervención armada poseían, para el autor, en la constitución de la ciudadanía y como modo de acceso al poder. Pero además, escenifica el modo restrictivo en que se define la ciudadanía en el texto, lo que está relacionado con el papel protagónico que Sarmiento le adjudicó a las élites en el proceso de consolidación nacional.

Son tres las escenas claves que ilustran el acceso a la ciudadanía en el texto. La más breve y menos definitoria para el destino futuro de Dominguito es la del voto. A los seis años, oye discutir en el círculo del padre sobre las elecciones y le pregunta cómo se vota y si puede votar. El padre le explica y luego, súbitamente, el niño desaparece: se ha ido a votar (Sarmiento, 1900, p. 193). Lejos de la solemnidad de un acto de iniciación a la ciudadanía, el evento de la votación aparece como una travesura infantil. Está narrado en tono humorístico, que resalta el encanto y la gracia del niño y la facilidad que tiene para ganarse el favor de los adultos: en lugar de reprimirlo o castigarlo por creerse munido de derechos que en realidad no posee, los mayores entran en su juego. El pasaje, que pone en escena el proceso de determinación y adjudicación del derecho al voto y correlativamente, a la ciudadanía, revela no la ampliación del acceso a los derechos cívicos sino la banalización del sufragio, vuelto pantomima, "broma", simulacro jocoso. Allí la ciudadanía aparece no como la consecución de una serie de derechos, sino como una "ilusión generosa”, una percepción puramente superficial producto del juicio particular del sujeto que, sin conciencia de sus limitaciones, se juzga munido de derechos. 
La segunda de las vías por las que Dominguito adquiere ciudadanía es la alfabetización, la lectoescritura. Dominguito aprende a leer y a escribir con su padre y desde niño participa y asiste a los círculos culturales y de la sociabilidad paterna lo que, mucho más que cualquier institución pedagógica y pública, lo inicia en la ciudadanía y en los sucesos de la política nacional. La escena de la iniciación del hijo a la letra es central en el texto, determinante del destino de Dominguito y de su participación en los destinos del país. El hijo aprende a escribir junto con el padre, que oficia de maestro y guía:

A los tres años de edad y por vía de entretenimiento, propúsose su padre enseñarle a leer, jugueteando, y como medio de excitar su curiosidad e inteligencia que se mostraba despierta y clara a tan temprana edad. [...] el niño de tres años iluminándosele el semblante con los rayos de la inteligencia que asomaba a sus ojos - papá, dijo, a que yo escribo Sarmiento? - a que no? - a que si; y escribió en la página en blanco de un librito lo que va al frente en facsímile. Esta es la copia exacta de aquella suprema evidencia de la concepción del niño a los tres y medio años. El librito en blanco existe en poder de la madre y es guardado como una reliquia, pues que allí han quedado rastros indelebles del pasaje de un alma que se despierta y camina (Sarmiento, 1900, p. 185) (sic en el original).

El pasaje ilustra de modo significativo el sentido iniciático del aprendizaje de la lectura: se trata de un verdadero despertar por el cual el padre atrae al niño al mundo de las letras. Significativamente, aparece la escritura del propio nombre, que también es el nombre del padre. La primera firma del niño - incluida en el texto como imagen litografiada - inscribe el nombre de ambos y representa el aprendizaje como intercambio y desafío entre padre e hijo 
"- papá, dijo, a que yo escribo Sarmiento? - a que no? - a que si" (sic en el original). La imagen representa la escritura imperfecta, tentativa, del niño. La firma, así como el cuaderno del cual se la ha extraído, constituyen "reliquias" de su despertar al mundo de las letras: es un rastro desordenado, un "informe", un verdadero "prontuario" que funciona como huella del acceso del niño pequeño a la ciudadanía letrada.

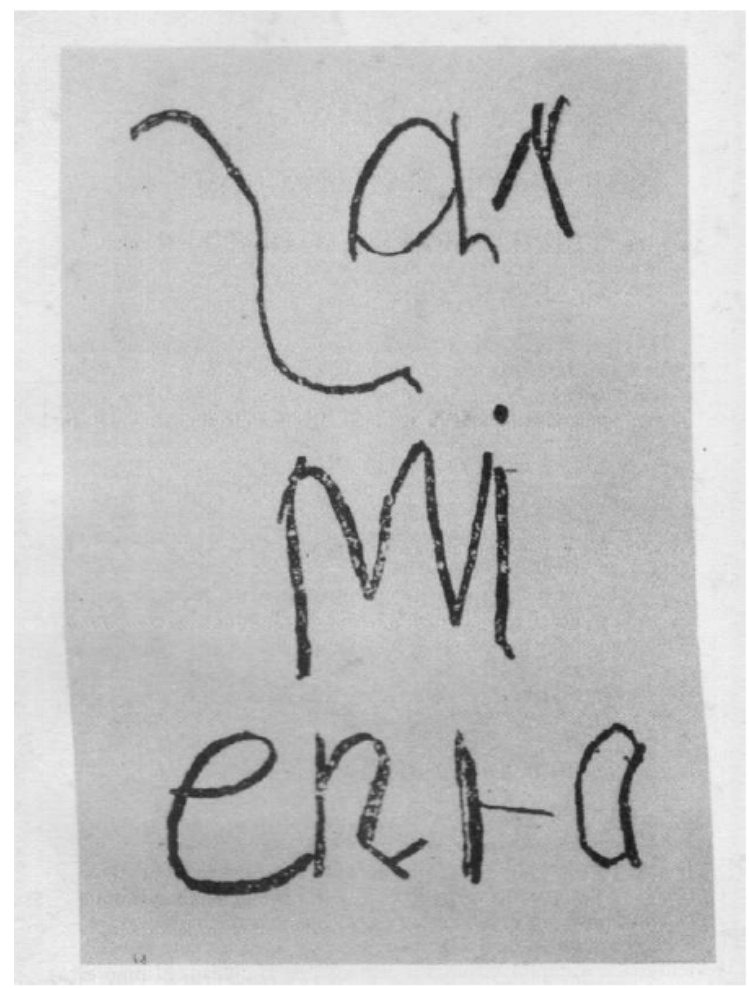

Sarmiento (1900, p. 185)

La firma constituye la marca de una escena de filiación, el acto de dar y recibir el nombre, que reactualiza el reconocimiento de la paternidad por parte de Sarmiento. El nombre del padre se lee en la firma del hijo, volviéndose 
indistinguibles uno del otro, lo que apunta a la lectoescritura como modo de acceso a la ciudadanía y símbolo del legado de Sarmiento.

Asociado a esta escena fundamental de aprendizaje paterno-filial se halla el contacto con los círculos políticos, culturales y de la sociabilidad del padre, junto a las múltiples lecturas de revistas y enciclopedias europeas. Munido de este capital cultural, el niño entra a la escuela, experiencia que resulta repetidamente fracasada o interrumpida: “...se pervertía o se atrasaba en los colegios, y sólo yo tenía poder para traerlo al buen camino, porque sólo yo conocía el resorte de su alma que era la gloria, la estimación y el aplauso." (Sarmiento, 1900, p. 180). Poco contribuye la institución escolar - mucho menos la educación pública defendida por Sarmiento - al desarrollo del intelecto de Dominguito: es sobre todo el influjo del padre que lo conduce y lo estimula al aprendizaje. En contraste con el carácter "vulgar", "ordinario" "por mayor" de la enseñanza escolar, la formación de Dominguito es un intercambio entre dos, orientado por la búsqueda de gloria, estimación y exaltación individual del discípulo.

Cuando entra en el Colegio y en la Universidad, Dominguito adquiere un status privilegiado entre sus compañeros por el contacto con los círculos y las lecturas a que tiene acceso a través del padre (Sarmiento, 1900, pp. 225226). Forma parte de asociaciones y se rebela junto con otros estudiantes, lo que le valdrá su expulsión de los colegios a los que asiste en Santiago de Chile y en Buenos Aires. Esto, lejos de ser leído por el padre como un fracaso, es visto como confirmación de sus dotes de liderazgo (Sarmiento, 1900, p. 224). De este modo, el ámbito escolar, más que un espacio de aprendizaje de materiales nuevos, es para Dominguito un campo de prueba, ejercicio y exhibición de las dotes políticas que le vienen dadas por herencia y formación paterna. Como un verdadero caudillo carismático, 
Dominguito lidera su círculo, se involucra en conspiraciones y proclama ideas revolucionarias, gracias a su familiaridad con espacios, personajes y acontecimientos políticos.

Dominguito participa de clubes de estudiantes, tertulias, salones literarios y sociedades, publica artículos en periódicos y colecciones, interviene en la esfera pública y, tentativamente, en la política. En la universidad, estudia derecho y, si bien sus resultados académicos son mediocres, funda un Club de Estudiantes, el cual preside, escribe piezas de crítica literaria y traducciones y forma varias sociedades de jóvenes. Como letrado incipiente y hombre público, forma parte de las múltiples modalidades de la sociabilidad que servían como resortes fundamentales de la formación de la ciudadanía, vías de iniciación al poder político. Dominguito ocupa en ellas un lugar excepcional y de liderazgo, de hombre notable entre otros notables, a lo que contribuyen su origen y su capital cultural que lo 60 singulariza entre sus compañeros. Es en esos círculos de la vida civil, más que en la educación formal, que sobresale Dominguito, dada su desordenada formación universitaria (Sarmiento, 1900, p. 239). Involucrado en la vida pública y política, el Dominguito estudiante abandona o descuida su pasaje por el Colegio y la Universidad.

La tercera vía de constitución de la ciudadanía es la carrera militar, la participación en el ejército y la intervención armada como modo de acceso a los derechos políticos. Vida de Dominguito se revela, en este sentido, como un texto en sintonía con su época, dado el rol crucial que, durante las dos últimas décadas del Siglo XIX, y con el ascenso de Julio A. Roca al poder, ocupó la cuestión militar y los líderes militares en la política argentina ${ }^{9}$. Dominguito se vuelve ciudadano activo cuando adquiere el derecho y la obligación

\footnotetext{
9 David Viñas ha señalado la importancia del militarismo en la trayectoria y en la obra de Sarmiento y sus conexiones con el ala conservadora de la Generación de 1880 (1994).
} 
de llevar armas para el país y es a partir del ejercicio de la vía armada que pretende ganarse su lugar como líder político.

La vocación militar del hijo se prefigura ya en la infancia, cuando aprende a montar, símbolo del dominio de lo salvaje, modo fundamental de iniciación a la ciudadanía en Hispanoamérica (Sarmiento, 1900, p. 199). Una vez en Buenos Aires, se convierte en un "patriota anticipado", un "político imberbe", a través de la vía de las armas:

Como de resistir a la imposición del nuevo orden de cosas se trataba, necesitábanse soldados en número suficiente para oponer a los que podía reclutar la Confederación, sin peligro de oposiciones voluntarias en trece provincias, en las que predominaban las clases abyectas. No pudiendo el Estado de Buenos Aires extender a mayor radio de territorio la ciudadanía, ni naturalizar de golpe extranjeros que recién empezaban a acudir a sus playas, la ley habilitó la edad a los púberes, admitiéndoles a la defensa del país a los 18 años de edad, con el aditamento de poder ejercer los derechos de ciudadanía. (Sarmiento, 1900, p. 222)

Sarmiento les adjudica a las élites porteñas un rol providencial en el proceso de consolidación del Estado Nacional argentino, como garantes de la hegemonía del gobierno unificado sobre las "clases abyectas" de las provincias, potencialmente díscolas. Es en virtud del papel de las élites, constructoras de un nuevo consenso sobre el modo de organización nacional, que los jóvenes educados, entre ellos Dominguito, adquieren un rol central, como ciudadanos precoces y con derechos. El carácter inmaduro del proceso de formación nacional determina, en la perspectiva de Sarmiento, el modo en que se define la ciudadanía, marcada por características juveniles: fuerza, virilidad, entusiasmo, abnegación y apasionamiento. En este sentido, Dominguito aparece como representativo y coincidente con su época y 
su "pueblo" - definido este de un modo altamente restrictivo, excluyendo a los inmigrantes y a la población de las provincias -, como caracterizado por la vivacidad, la fortaleza, la determinación y el patriotismo, pero también por la falta de disciplina y el exceso.

Así, al enrolarse en el ejército como Capitán en la Guerra del Paraguay, Dominguito encarnaría el rol que les cabe a las élites porteñas en la defensa de los ideales ilustrados, contrarrestando el ímpetu expansionista y tiránico que caracterizaba, en la perspectiva de Sarmiento, al régimen de Solano López (Sarmiento, 1900, pp. 245-246). Este destino honroso de las clases altas porteñas tendría en la muerte de Dominguito su emblema, no sólo por su participación entusiasta en la guerra ("Dominguito fue el primero de los enrolados"), sino también porque encarna una conjunción de iniciativa personal con status y formación dada por el padre. La vocación militar de Dominguito es producto tanto 62 de la voluntad férrea de "endurecerse", de la abnegación y el esfuerzo bélico, como de la formación paterna para la vida pública y el gobierno (Sarmiento, 1900, p. 247). Se trata de un ideal de hombre público y gobernante que considera la destreza personal, la fuerza guerrera y la pertenencia a un linaje como características entrelazadas y ligadas fuertemente a la ilustración. La determinación que Dominguito demuestra en su iniciación a las letras y a las armas viene sólo a confirmar su destino de gobierno y la centralidad de la propia herencia y formación paternas.

\section{Ficciones de la paternidad y el buen morir}

Con el propósito de reconstruir la escena de la muerte del hijo, Sarmiento reúne una amplia cantidad de materiales: cartas de pésame, noticias de diarios y testimonios. También cita cartas de la madre y el cuaderno que llevaba el hijo al morir, suerte de diario de guerra, de donde cita sus últimas anotaciones: "Morir por su patria es vivir, es dar 
a nuestro nombre un brillo que nada borrará” y a continuación "Son las diez. Las balas de grueso calibre estallan sobre el batallón. Salud mi madre!” (Sarmiento, 1900, p. 259) (sic en el original). A través del montaje de estos materiales, Sarmiento construye una representación de la muerte de Dominguito como una "buena muerte", una muerte gloriosa, valiente, viril ${ }^{10}$. Esta operación de inclusión y montaje de cartas de condolencias, testimonios, anotaciones del diario de batalla y las últimas palabras responde al propósito de conferir sentido y propósito a la pérdida, describiendo los últimos momentos y funcionando como memento mori, reliquias que representan y retienen el espíritu del fallecido. Como ficción del "buen morir", esta declaración mortuoria, recuperada por Sarmiento en el epígrafe, relaciona el acto de morir en la batalla con la iniciación a la ciudadanía. Y apela, por otro lado, a la generación que había luchado en la Guerra Paraguay, que eran los hombres públicos, intelectuales y políticos de 1880, en quienes deposita la tarea de la unificación nacional. De este modo, el sacrificio de Dominguito funciona como símbolo de un nuevo tipo de hegemonía y de un nuevo consenso, propio de la nación unificada, que emerge como resultado de la Guerra del Paraguay y se define a través de la lucha militar. Sarmiento se coloca a sí mismo y a su hijo en el lugar de artífices y predecesores de este proceso.

Como se ve, ante la ausencia del heredero, Sarmiento construye y adopta, a través de la biografía de Dominguito, un legado y una filiación escrituraria. En Sarmiento la paternidad, lejos de un hecho únicamente individual, adquiere un sentido político, íntimamente ligado a su proyecto de construcción nacional y a un sentimiento patriótico y colectivo. Sarmiento reinventa y reconstruye el lazo paterno-filial

\footnotetext{
10 Para el tema de las "ficciones del buen morir" o de la "buena muerte" en la Guerra Civil norteamericana, ver Faust (2008, p. 29).
} 
en la escritura, y le confiere un sentido profundamente patrio: es a partir de una matriz paterno-filial que piensa su legado para la Argentina futura.

Central en este sentido es el tema de la adopción. Afirma: "Nació Domingo Fidel Castro en Santiago de Chile el 17 de abril de 1845 y pasando más tarde a segundas nupcias su madre, de procedencia argentina, fue por adopción, cambiado su apellido por el de Sarmiento, que le fue nombrado tutor, a fin de que nada enfriase los afectos de la nueva familia." (Sarmiento, 1900, p. 183). La escena de filiación aparece como la formación de una "nueva familia" de "afectos", que no parte de lazos biológicos, sino de una elección voluntaria y deliberada, en la cual el padre adopta al hijo, le da su apellido y se vuelve su maestro y tutor. Se trata de una concepción de la familia dada no por una obligación mutua, sino por mutua elección, "a fuerza de hábito" - dice Rousseau en Du Contrat Social ou Principes Du Droit Politique (1762) - ligada a una idea de filiación contingente y contractual. Este esquema de filiación lleva implícita una idea democrática de gobierno que, en lugar de imponer una autoridad absoluta, es producto de una mutua elección entre el gobernante y los gobernados. El propio Benjamin Franklin había pensado la cuestión de la adopción, ligada a su doctrina individualista de construcción del sí mismo y de nuevos comienzos (independiente de la herencia y de los lazos de sangre), y conectada con su visión de la educación como motor de mejoramiento personal y de autonomía ${ }^{11}$. Sin embargo, Vida de Dominguito escenifica la formación del hijo menos como producto del esfuerzo personal y más como profundamente determinada por la pertenencia al círculo, a la genealogía y al linaje paternos, lo cual resulta paradójico

\footnotetext{
11 Para un análisis de la representación de la adopción en la literatura del Iluminismo y el Siglo XIX norteamericano, y en particular en Benjamin Franklin, ver Singley (2011, p. 49).
} 
si consideramos su condición de adoptado. A pesar de los vaivenes que sufre la relación entre padre e hijo, separados por la distancia geográfica, los puestos de gobierno y la propia muerte, la identidad de Dominguito aparece indeleblemente signada por la influencia y la autoridad del padre que se inscribe permanentemente en su biografía. Sarmiento aparece como punto de partida, origen y fundador del linaje patriótico e ilustrado del que Dominguito es señalado como heredero: su vida aparece como resultado y confirmación de un legado que constantemente retrotraen al padre como origen y sentido.

\section{Conclusión}

Ya en Recuerdos de Provincia (1849-1850), uno de los primeros textos autobiográficos latinoamericanos en otorgar un lugar significativo a la infancia (Miceli y Myers, 2016), el niño ponía en escena el conflicto entre la nostalgia por el modo de vida colonial, representado por la casa materna, y el nuevo modelo de ciudadanía democrática al que Sarmiento accedía en la escuela recién fundada (Prieto, 1996, p. 60). Esto sólo se intensifica en Vida de Dominguito, en que la infancia ocupa un lugar aún más central. Ya desde la escena de la adopción, el texto apunta a un ideal democrático que concibe el lazo paterno-filial no como dado por la biología y la pertenencia a una estirpe de sangre, sino como resultado de la mutua elección y el libre arbitrio. Sarmiento le da a Dominguito su apellido y, al iniciarse en la escritura a los tres años, el hijo estampa su firma, "Sarmiento", señalando el carácter de mutuo acuerdo, voluntario y contractual de la filiación. La escena de iniciación en la lectoescritura, protagonizada por padre e hijo, representa el acceso a la ciudadanía como instancia democrática fundamental de formación a la vez intelectual y afectiva, a partir de las capacidades individuales. Dominguito es un niño ávido 
de conocimiento, inteligente, carismático y valiente: es a la vez un pequeño intelectual, un héroe militar, un hombre público y futuro estadista.

Ahora bien, paradójicamente, estas virtudes, de las que Dominguito aparece como precoz y excepcional portador, están íntimamente asociadas a su pertenencia a un linaje de antepasados prestigiosos del cual el propio Sarmiento se presenta como punto de partida y fundador. Es así que los frecuentes actos de indisciplina, excesos y rebeldías no generan reflexión, arrepentimiento o aprendizaje en el discípulo, y son leídas por el padre como confirmaciones inequívocas de su carácter excepcional, su aptitud como hombre público y miembro de la élite gobernante. Esto es así porque allí la virtud patriótica, la ilustración y la pertenencia a un linaje van de la mano y ratifican una a la otra. Su muerte sacrificial y patriótica, en lugar de refutar ese destino, lo confirma como mártir de la consolidación de la Argentina futura y contribuye a alejar los fantasmas de ascensión de las clases populares y de las provincias a la nacionalidad. Esto distancia al protagonista definitivamente del modelo de hombre moderno, práctico, producto del propio esfuerzo: Dominguito se perfila, más que como un self-made man, como un héroe militar, valeroso, abnegado, pero también excesivo e indisciplinado. En la lectura de Sarmiento, este carácter desmesurado del héroe sería coherente con una Argentina aún inmadura, en que las élites gobernantes serían las únicas capaces de asegurar la consolidación nacional, y cuyo círculo debería excluir a las clases populares y a las poblaciones de las provincias, que se consideraban aún portadoras de trazos heredados de barbarie. Vida de Dominguito es una biografía del hijo en que el lazo paterno-filial revela el legado ambivalente de Sarmiento, entre la formación intelectual y afectiva en un modelo de ciudadanía democrática y emancipación intelectual, y la pertenencia a un linaje y a una élite gobernante que define de modo altamente restrictivo los límites de la nacionalidad y de la ciudadanía. 


\section{Alejandra Josiowicz}

é investigadora assistente do Consejo Nacional de Investigaciones Científicas y Técnicas (CONICET). Tem experiência nas áreas de Sociologia da Cultura e da Educação e de Estudos Culturais na América Latina. Licenciada em Letras pela Universidade de Buenos Aires (UBA), é mestre e doutora em Spanish and Portuguese pela Princeton University (PU). Realizou estágio de pós-doutoramento no Programa de PósGraduação em História das Ciências e da Saúde (PPGHCS) da Casa de Oswaldo Cruz (COC/Fiocruz). Foi professora assistente no Programa de Estudos Latino-americanos da Rutgers University (RU). Publicou artigos em revistas nacionais e internacionais e recebeu bolsas da Princeton University, da Cornell University (CU) e da CAPES/FAPERJ.

\section{Bibliografía}

ANDERSON IMBERT, Enrique. 1967. Genio y figura de Sarmiento. Buenos Aires: Eudeba. 1975. Génesis del primer Dominguito. Nueva Revista de Filología Hispánica, Ciudad de México, DF, v. 24, n. 2, pp. 504-509.

ALTAMIRANO, Carlos; SARLO, Beatriz. 1997. Una vida ejemplar: la estrategia de Recuerdos de Provincia. In: Ensayos argentinos: de Sarmiento a la vanguardia. Buenos Aires: Ariel. pp. 103-160.

BRIZUELA AYBAR, Eduardo. 1988. Dominguito: texto y contexto. San Juan: Universidad Nacional de San Juan.

DORATIOTO, Francisco. 2002. Maldita guerra: nova história da Guerra do Paraguai. São Paulo: Companhia das Letras.

DOSSE, François. 2009. O desafio biográfico: escrever uma vida. São Paulo: Edusp. FARIÑA NUÑEZ, Porfirio. 1934. Los amores de Sarmiento. Buenos Aires: Tor. FAUST, Drew Gilpin. 2008. This republic of suffering: death and the American civil war. New York: Alfred Knopf.

HALPERÍN DONGHI, Tulio. 1980. Una nación para el desierto Argentino. In: (ed.). Proyecto y construcción de una nación:

Argentina, 1846-1880. Caracas: Biblioteca Ayacucho, pp. 12-101. 1989. El antiguo orden y su crisis como tema de Recuerdos de Provincia. Boletín del Instituto de Historia Argentina y Americana "Dr. Emilio Ravignani", Buenos Aires, v. 3. n. 1, pp. 7-22. 
1994. Sarmiento's place in post-revolutionary Argentina. In:

HALPERÍN DONGHI, Tulio et al. (eds.). Sarmiento: author of a nation.

Berkeley: University of California Press, pp. 19-30.

1997. Historia contemporánea de América Latina. 13. ed. Madrid: Alianza.

HALBWACHS, Maurice. 1992. On collective memory. Chicago: University of Chicago Press.

LEJEUNE, Philippe. 1975. Le pacte autobiographique. Paris: Seuil.

LEUCHARS, Chris. 2002. To the bitter end: Paraguay and the War of the Triple Alliance. Westport, CT: Greenwood.

MICELI, Sérgio; MYERS, Jorge. 2016. Introducción al dossier "El duro deseo de durar": Retratos latinoamericanos en la periautografía de los intelectuales del siglo XX. Políticas de la Memoria, Buenos Aires, n. 17, pp. 10-32.

MOLLOY, Sylvia. 1992. At face value: autobiographical writing in Spanish America. Cambridge, MA: Cambridge University Press.

PRIETO, Adolfo. 1966. La literatura autobiográfica argentina. Buenos Aires: Jorge Álvarez.

ROSA, Nicolás. 1990. El arte del olvido: sobre la autobiografía. Buenos Aires: Puntosur.

SÁBATO, Hilda. 2001. On political citizenship in nineteenth-century Latin America. The American Historical Review, Oxford, v. 106, n. 4, pp. 1290-1315.

SARLO, Beatriz. 2012. Sarmiento en el Siglo XX. In: JITRIK, Noé (dir.). Historia crítica de la literatura argentina. Buenos Aires: Emecé, v. 4.

SARMIENTO, Domingo Faustino. 1886. La vida de Dominguito: in memoriam del valiente y deplorado capitán Domingo Fidel Sarmiento: muerto en Curupaití a los veinte años de edad: autor de varios escritos, biografias y correspondencias y traductor de "París en América". Buenos Aires: Sociedad Tipográfica "El Censor". 1899. Obras de D. F. Sarmiento: ideas pedagógicas. Buenos Aires: Belin Hermanos, v. 28. . 1900. Obras de D. F. Sarmiento: vida de Dominguito. Buenos Aires:

Belin Hermanos, v. 45. . 2000. La vida de Dominguito. Buenos Aires: Fondo Nacional de las Artes.

SINGLEY, Carol. 2011. Adopting America: childhood, kinship, and national identity in literature. Oxford: Oxford University Press.

VIÑAS, David. 1994. Madness or accumulation. In: HALPERÍN DONGHI, Tulio et al. (eds.). Sarmiento: author of a nation. Berkeley: University of California Press, pp. 213-219. 


\section{LA VIDA DE DOMINGUITO: CIUDADANÍA, PATERNIDAD Y GUERRA EN DOMINGO FAUSTINO SARMIENTO}

\section{ALEJANDRA JOSIOWICZ}

Resumen: Este artículo analiza La vida de Dominguito (1886) de Domingo Faustino Sarmiento, biografía del hijo adoptivo, Domingo Fidel Sarmiento, muerto en la Guerra del Paraguay. La vida de Dominguito está ligada a la última etapa de la trayectoria intelectual y política de Sarmiento y escenifica el lugar central de la Guerra del Paraguay en el proceso de consolidación del Estado nacional argentino. La vida de Dominguito es examinada en relación con los textos biográficos, autobiográficos y pedagógicos de Sarmiento. La biografía del hijo revela los desafíos en el proceso de consolidación nacional, el papel central que Sarmiento adjudica a las élites militares e ilustradas y las tensiones de su ideal democrático de educación. El foco del análisis es la representación del acceso precoz del hijo a la ciudadanía, a partir de tres modalidades fundamentales: el sufragio, las armas y las letras. En la conclusión, se reflexiona sobre el sentido histórico-político de la paternidad, la infancia y la filiación.

Palabras clave: Domingo Faustino Sarmiento; La vida de Dominguito; Ciudadanía; Paternidad; Guerra del Paraguay; Pensamiento Social.

\section{LA VIDA DE DOMINGUITO: CIDADANIA, PATERNIDADE E GUERRA EM DOMINGO FAUSTINO SARMIENTO}

Resumo: Este artigo analisa La vida de Dominguito (1886), de Domingo Faustino Sarmiento, biografia de seu filho adotivo, Domingo Fidel Sarmiento, morto na Guerra do Paraguai. La vida de Dominguito está ligada à última etapa da trajetória intelectual e política de Sarmiento e revela o lugar central da Guerra do Paraguai no processo de consolidação do Estado nacional argentino. 
La vida de Dominguito é examinada em relação aos textos biográficos, autobiográficos e pedagógicos de Sarmiento. A biografia do filho revela os desafios no processo de consolidação nacional, o papel central que Sarmiento adjudica às elites militares e letradas, $e$ as tensões de seu ideal democrático de educação. O foco da análise é a representação do acesso precoce do filho à cidadania a partir de três modalidades fundamentais: o sufrágio, a iniciação às armas e às letras. A conclusão, inclui uma reflexão sobre o sentido histórico-político da paternidade, a infância e a filiação.

Palavras-chave: Domingo Faustino Sarmiento; La vida de Dominguito; Cidadania; Paternidade; Guerra do Paraguai; Pensamento Social.

\section{LA VIDA DE DOMINGUITO: CITIZENSHIP, FATHERHOOD AND WAR IN DOMINGO FAUSTINO SARMIENTO}

Abstract: This article examines La vida de Dominguito (1886), by Domingo Faustino Sarmiento, the biography of his adopted son, Domingo Fidel Sarmiento, who died in the Paraguayan War. La vida de Dominguito is linked to the last period of Sarmiento's intellectual and political life, and reveals the centrality of the Paraguayan War in the Argentinian process of national consolidation. This article considers La vida de Dominguito in relation to Sarmiento's biographies, autobiographies and pedagogical texts. His son's biography reveals the challenges in the process of national consolidation, the central role he adjudicates to the military and lettered elites and the tensions of his democratic ideal of education. The analysis focuses on the representation of his son's precocious access to citizenship through three different channels: the vote, the military and education. Finally, it reflects on the historical and political signification of paternity, childhood and filiation.

Keywords: Domingo Faustino Sarmiento; La vida de Dominguito; Citizenship; Fatherhood; Paraguayan War; Social Thought.

Recebido: 20/02/2017

Aprovado: 11/12/2017 